8 - ORIGINAL ARTICLE

EXPERIMENTAL CARDIOVASCULAR SURGERY

\title{
The intervention research on treatment by Xianchen to rabbits model of chemotherapeutic phlebitis ${ }^{1}$
}

\author{
Jing Zhang', Juan Shen" ${ }^{\mathrm{II}}$, Weiwei Yin ${ }^{\mathrm{II}}$, Xiaoyu Wei ${ }^{\mathrm{III}}$, Ligao Wu ${ }^{\mathrm{IV}}$, Hao Liu \\ DOI: http://dx.doi.org/10.1590/S0102-865020160080000008 \\ IFull Professor, Department of Nursing, Bengbu Medical College, China. Conception and design of the study, critical revision.

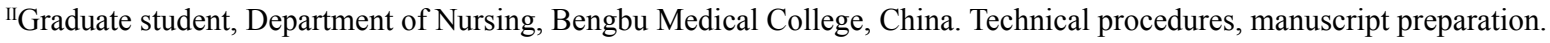 \\ III Graduate student, Department of Nursing, Bengbu Medical College, China. Technical procedures. \\ ${ }^{\mathrm{IV}}$ Assistant Professor, Department of Pathology, First Hospital Affiliated to Bengbu Medical College, China. Histopathological examinations. \\ ${ }^{v}$ Full Professor, Department of Pharmacology, Bengbu Medical College, China. Conception and design of the study.
}

\begin{abstract}
PURPOSE: To develop a chemotherapeutics induced phlebitis and explore the effects of Xianchen on the phlebitis treatment. METHODS: Forty-eight rabbits were divided into two series. Phlebitis model induced by vincristine was established at each series. The first series had 24 rabbits, which were divided into four groups (6 hours, 12 hours, 18 hours, 24 hours) after vincristine infusion. The grades of phlebitis through visual observation and histopathological examination were observed. The second series had also 24 rabbits. Interventions were performed 12 hours after vincristine infusion. These rabbits were randomly divided into four groups, according to treatment: Hirudoid (bid), Xianchen (daily), Xianchen (tid), Xianchen (five times a day). Four days after intervention, the venous injury through visual observation and histopathological examination were evaluated.

RESULTS: Series 1: Phlebitis appeared 12 hours after infusion of vincristine through visual observation. There was a significant difference $(\mathrm{p}<0.05)$ between 6 hours and 24 hours, 6 hours and 18 hours through visual observation. However, the inflammation happened 6 hours after infusion, the loss of venous endothelial cells demonstrated differences among four groups through histopathological evaluation $(p<0.05)$. There were significant differences $(p<0.05)$ after 4 days among the intervention groups through visual observation, the effects of Xianchen group (five times a day) were better than Xianchen group (tid) $(\mathrm{p}<0.01)$. The treatment of edema demonstrated differences among groups through histopathological evaluation $(\mathrm{p}<0.05)$, Xianchen (five times a day) better relieved the degree of edema $(\mathrm{p}<0.05)$.

CONCLUSIONS: The study showed that inflammatory reaction of phlebitis appeared early. Xianchen can treat vincristine induced phlebitis, as well as Hirudoid. It is particularly effective in the treatment of edema, and there is a remarkable dose-response relationship. Key words: Phlebitis. Xianchen. Rabbits.
\end{abstract}




\section{Introduction}

Chemotherapy is widely used as a systemic method in cancer treatment such as "Cytotoxic" drugs ${ }^{1}$. Antineoplastic agents for the treatment of cancer have narrow therapeutic margins characteristically, leading to significant adverse effects. Phlebitis is more prevalent with nitrogen mustard, anthracyclines, vinca alkaloids, and nitrosoureas. Vinca alkaloids include vincristine, vinorebine, and velban, and the mechanism of vincristine is to inhibit mitosis by binding tubulin. However, it has several side effects, such as neurovirulence, myelosuppression, local stimulation, etc. Infusion phlebitis, an immediate and local toxicity, is one of the common chemotherapy induced disease ${ }^{2}$. It is defined as "sterile inflammation of the vein, which may be accompanied by pain, erythema, edema, treak formation, and/or palpable cord"3. The sterile inflammation caused by the antineoplastic drug stimulates the wall of blood vessels. One reason for that is the chemotherapy always has multiple courses, and patients need to get long and repeated infusion therapy and the antineoplastic drugs have strong stimulation to vessels ${ }^{4-6}$. Another reason is that antineoplastic drugs possess cellular and chemical toxicity ${ }^{7}$. Lastly, the immune system of the patient with tumour is usually compromised and vulnerable to phlebitis ${ }^{8,9}$. Research shows that about $70 \%$ of patients develop phlebitis when receiving antineoplastic drugs infusion ${ }^{1}$, which often causes the treatment discontinued.

The pathogenesis of infusion phlebitis still remains unclear even though a number of methods for avoiding phlebitis have been reported ${ }^{10}$, such as the rapid injection, dilution of infusion solution and application of anti-inflammatory topical drugs, or corticosteroid. However, none are completely effective ${ }^{11}$.

Vincristine is vinca alkaloid derived from vinblastine and is employed to treat acute leukaemia, small cell lung cancer and breast cancer. Vincristine is often used together with other chemotherapeutic drugs such as endoxan and cisplation. It has been associated with more favorable therapeutic outcomes. However, vincristine is also associated with toxicity due to its harm to nerves and vessels. The current study has shown vincristine could cause phlebitis via intravenous infusion ${ }^{12}$.

In recent years, discoveries have confirmed the use of Chinese herbal to prevent phlebitis induced by chemotherapy in clinic $^{13}$, such as Ruyi Jinghuang Powder, protection veins ointment, which their effective heat-clearing and relief of internal heat, can improve the blood circulation and apocatastasis ${ }^{14-15}$. However, some ingredients of Xianchen also had the effects above, such as fritillaria, bletilla striata. Study has proved that Xianchen could remove edema ${ }^{16}$.This study had two series, the first series sought to investigate the development of vincristine induced phlebitis in early time. The second series explore the effect of Xianchen, made from several traditional Chinese herbs, on the phlebitis induced by vincristine.

\section{Methods}

This study was approved by the Ethics Committee of Bengbu Medical College.

Forty-eight New Zealand rabbits were provided by the Laboratory Animal Center of Bengbu Medical College (Anhui, China), weighting range from 1.83 to $2.84 \mathrm{~kg}$. They were housed in individual cages in an animal room with temperature at $24 \pm 0.5^{\circ} \mathrm{C}$, $60 \pm 5 \%$ of humidity, and a 12-hour light-dark cycle. All rabbits were allowed free access to diet and water.

\section{Drugs}

Vincristine Sulfate of Injection (VCR, $1 \mathrm{mg}$, Wanle Pharmaceutical Co., LTD, Shenzhen, China) was provided by the First Affiliated Hospital to Bengbu Medical College. The $10 \mathrm{ml}$ infusion solution included $0.2 \mathrm{mg} / \mathrm{kg}$ of VCR dilution. Therefore, a $1 \mathrm{mg}$ vial of VCR was diluted with $10 \mathrm{ml}$ of normal saline (Huayu Pharmace utical Co., LTD, Wuxi, China).

The drugs for intervention were Xianchen (Xian Chen Acne Clear, $10 \mathrm{ml}$, Zeping pharmaceutical co., LTD of Anhui Province, China, batch number: ZG10110) and Hirudoid (Mucopolysaaccharide Polysulfate, 14g, Mobilat Produktion GmbH, Germany, batch number: 201227).

\section{Experimental process}

In the first series, $24 \mathrm{New}$ Zealand rabbits were randomly divided into four groups ( 6 rabbits per group), including 6 hours after intravenous infusion (6h), 12 hours after intravenous infusion (12h), 18 hours after intravenous infusion (18h) and 24 hours after intravenous infusion (24h). Auricular veins of all rabbits were punctured reversely and infused with VCR at an injection speed of $30 \mathrm{ml} / \mathrm{h}$ via infusion pump. The point of puncture was about $2 \mathrm{~cm}$ distance to the lower root of rabbit's auricle, flushed with $2 \mathrm{~mL}$ normal saline before and after infusion respectively. The experimental method was showed in Figure 1. 


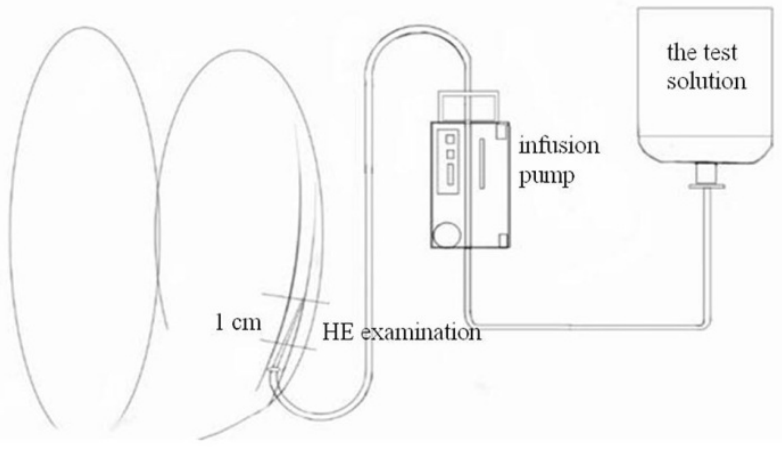

FIGURE 1 - Site of histopathological examination. The region of the ear vein was located at the $1 \mathrm{~cm}$ from the puncture point to the needle point, and it was sampled at 6 hours, 12 hours, 18 hours and 24 hours after VCR infusion respectively.

Each rabbit's ear was given skin preparation before the test, using animal electric razor (Codos electronics factory, Shenzhen, China). Infusion solution was infused through disposable infusion device (Lotus medical supplies co., LTD, Henan, China). Disposable scalp vein set (Shuguang jianshi medical equipment group co., LTD, Shenzhen, China) connected with disposable infusion device was used to puncture auricular vein, then infusion band (Jingwei medical instrument co., LTD, Jiangsu, China) was used to secure the scalp vein set. The injection sites were marked by picric acid. Samples were obtained from the marked area after rabbits were under anesthesia which was administered with $10 \%$ chloralhydrate according to $2 \mathrm{ml} / \mathrm{kg}$ via another ear vein. The grades of phlebitis after infusion were judged by two operators via macroscopic and microscopic observation, and then confirmed the occurrence time of phlebitis.

In the second series, 24 rabbits were randomly divided into four groups, each group had six rabbits, including group of Hirudoid bid $(\mathrm{H})$, group of Xianchen daily (Xd), group of Xianchen tid (Xtid), group of Xianchen five times a day (X5).

In each rabbit was developed the model of phlebitis by the method used in Series 1. The time of intervention was 12 hours after infusion of VCR solution, and the area of intervention was centered on the puncture point. The drugs were directly applied along the blood vessels about $2 \sim 3 \mathrm{~cm}$ long, the dose of drug was $0.2 \mathrm{~mL}$ each time. The intervention method of each group was shown below. Xianchen (daily) was applied at 12:00. Hirudoid (bid) was applied at 8:00 and 14:00. Xianchen (tid) was applied at 8:00, 12:00 and 16:00. Xianchen (five times a day) was applied at 8:00, 10:00, 12:00, 14:00 and 16:00 every day. Four days after intervention, the level of venous injury was evaluated via macroscopic and microscopic observation.

\section{Indexes for phlebitis}

Perusal Macroscopic criterion was based on the American Infusion Nurses Society (INS) phlebitis scale, grading phlebitis from 0 (no symptoms) to 4 (all symptoms present: pain, erythema, edema, streak formation, palpable vein cord $>2.54 \mathrm{~cm}$ in length with purulent drainage) $)^{3}$. Grade 0 has no changes. Grade 1 means that appears erythema. Grade 2 appears erythema and edema. Grade 3 appears erythema, edema or not, streak formation. Grade 4 appears erythema, edema or not, palpable vein cord $>2.54 \mathrm{~cm}$ in length with purulent drainage.

Microscopic observation of ear marginal vein was stained with hematoxylin and eosin (HE). It was performed blindly and the findings were rated based on those of Kuwahara (Table 1)2,17,18. The specimens for histopathological examination were stored in paraformaldehyde. They were cut into two pieces $5 \mathrm{~mm}$ long with the cross sections of the ear vein in the Pathological Center. Each sample was paraffin embedded, made into sections and stained by hematoxylin and eosin. Each section was sectioned $0.5 \mu \mathrm{m}$ in thickness.

TABLE 1 - Criteria for histopathological examination.

\begin{tabular}{|c|c|}
\hline Histopathological findings & Grade \\
\hline \multicolumn{2}{|l|}{ Loss of venous endothelial cells } \\
\hline None & 0 \\
\hline Less than $1 / 3$ of the vein (in cross-section) & 1 \\
\hline $1 / 3$ to $2 / 3$ of the vein & 2 \\
\hline More than $2 / 3$ of the vein & 3 \\
\hline \multicolumn{2}{|l|}{ Inflammatory cell infiltration } \\
\hline None & 0 \\
\hline $\begin{array}{c}\text { Few inflammatory cells in venous wall or peri- } \\
\text { vascular tissue }\end{array}$ & 1 \\
\hline $\begin{array}{l}\text { Many inflammatory cells in venous wall or peri- } \\
\text { vascular tissue }\end{array}$ & 2 \\
\hline $\begin{array}{l}\text { More diffuse and dense inflammatory cells infil- } \\
\text { trates in perivascular tissue }\end{array}$ & 3 \\
\hline \multicolumn{2}{|l|}{ Edema } \\
\hline None & 0 \\
\hline Localized to perivascular tissue & 1 \\
\hline More diffuse edema & 2 \\
\hline Edema of the entire region & 3 \\
\hline \multicolumn{2}{|l|}{ Thrombosis } \\
\hline None & 0 \\
\hline$<1 / 3$ of vascular sections & 1 \\
\hline $1 / 3$ to $2 / 3$ of vascular sections & 2 \\
\hline More than $2 / 3$ of vascular sections & 3 \\
\hline
\end{tabular}

\section{Statistical analysis}

The grade of each finding was compared among groups by the Wilcoxon rank sum test and Mann-Whitney U test, $p<0.05$ 
was considered a significant difference. Data was analyzed using SPSS software version 16.0 (SPSS Inc., Chicago, IL, USA).

\section{Results}

\section{The longer the time was over, the worse the phlebitis} was

After VCR infusion, the vessels shrank and blanched, companied with rabbits' restlessness and struggling. Vascular injection point and surrounding area showed redness and swelling over time. In the whole experiment process, rabbits had no signs of death. There were no evident changes 6 hours after infusion. However, redness at the location of intravenous injection occurred 12 hours after infusion, and the vessels turned dark red and black 18 hours after infusion. The results showed that there was a meaningful statistical difference between 6 hours and 18 hours $(p<0.05), 6$ hours and 24 hours $(p<0.05), 12$ hours and 18 hours $(p<0.05), 12$ hours and 24 hours $(p<0.05)$ after infusion. Therefore, the longer the time was over, the worse phlebitis was $(\mathrm{p}<0.01)$ (Table 2).

TABLE 2 - The grade of phlebitis in different time of rabbits.

\begin{tabular}{|c|c|c|c|c|c|c|}
\hline \multirow[t]{2}{*}{ Grade } & \multirow{2}{*}{$\begin{array}{l}\text { Total numbers of } \\
\text { Intravenous observation }\end{array}$} & \multicolumn{5}{|c|}{$\begin{array}{l}\text { The grades of vein } \\
\text { damage }\end{array}$} \\
\hline & & 0 & 1 & 2 & 3 & 4 \\
\hline $6 \mathrm{~h}^{\mathrm{a}}$ & 6 & 6 & 0 & 0 & 0 & 0 \\
\hline $12 \mathrm{~h}^{\mathrm{b}}$ & 6 & 4 & 2 & 0 & 0 & 0 \\
\hline $18 \mathrm{~h}$ & 6 & 1 & 0 & 5 & 0 & 0 \\
\hline $24 \mathrm{~h}$ & 6 & 1 & 1 & 1 & 3 & 0 \\
\hline$p$ value & & & \multicolumn{4}{|c|}{$<0.01$} \\
\hline
\end{tabular}

6h: group of 6 hours after intravenous infusion; 12: group of 12 hours after intravenous infusion; 18h: group of 18 hours after intravenous infusion; 24h: group of 24 hours after intravenous infusion; "a" means $p$ value which indicated a significant difference between 6-hour and 18-hour ( $p<0.05), 6$ hours and 24 hours $(p<0.05)$; "b" means $p$ value which indicated a significant difference between 12 -hour and 18-hour ( $<<0.05), 12$ hours and 24 hours $(\mathrm{p}<0.05)$.

Table 3 summarized the histopathological findings obtained after VCR infusion in different time. Pathological results were judged at low power and high power of light microscope, which showed that the histopathological changes including loss of venous endothelial cells, inflammatory cell infiltration, edema and thrombosis. Six hours after the test solution was injected, the damages of veins and tissues were noted such as the loss of venous endothelial cells, inflammatory cell infiltration, edema and thrombosis. A significant difference was only found for loss of venous endothelial cells $(p<0.05)$, while differences of other three aspects were no statistically significant $(p>0.05)$. It also showed that the longer the time lasted, the more serious the phlebitis was, especially the loss of venous endothelial cells. After VCR infusion, there were three pieces demonstrating loss of venous endothelial cells after 6 hours, grading 1 2). Four pieces after 12 hours were rated grade $1 \sim 3$, and only one piece was graded 3 . Six pieces after 18 hours were evaluated grade 1 3; one piece was graded 3. Six pieces after 24 hours were graded 1 3; three pieces were grade 3 . Therefore, the loss of venous endothelial cells had a significant difference $(p<0.05)$ between 6 hours and 24 hours, 6 hours and 18 hours after infusion. In this study, the thrombosis appeared early, and the more time, the more serious the thrombosis, but the differences were not statistically significant.

TABLE 3 - The pathological grade of rabbit ear margin vein in different times.

\begin{tabular}{|c|c|c|c|c|}
\hline & $\begin{array}{c}\text { Loss of } \\
\text { venous endo- } \\
\text { thelial cells }\end{array}$ & $\begin{array}{l}\text { Inflamma- } \\
\text { tory cell } \\
\text { infiltration }\end{array}$ & Edema & Thrombosis \\
\hline Grade & $\begin{array}{llll}0 & 1 & 2 & 3\end{array}$ & $\begin{array}{llll}0 & 1 & 2 & 3\end{array}$ & $\begin{array}{llll}0 & 1 & 2 & 3\end{array}$ & $\begin{array}{llll}0 & 1 & 2 & 3\end{array}$ \\
\hline $6 h^{\mathrm{a}}$ & $\begin{array}{llll}3 & 2 & 1 & 0\end{array}$ & $\begin{array}{llll}0 & 2 & 3 & 1\end{array}$ & $\begin{array}{llll}0 & 4 & 1 & 1\end{array}$ & $\begin{array}{llll}3 & 1 & 1 & 1\end{array}$ \\
\hline $12 \mathrm{~h}$ & $\begin{array}{llll}2 & 1 & 2 & 1\end{array}$ & 0222 & $\begin{array}{llll}0 & 3 & 2 & 1\end{array}$ & 14401 \\
\hline $18 \mathrm{~h}$ & $\begin{array}{llll}0 & 2 & 3 & 1\end{array}$ & $\begin{array}{llll}0 & 1 & 4 & 1\end{array}$ & $\begin{array}{llll}0 & 5 & 0 & 1\end{array}$ & $23 \quad 301$ \\
\hline $24 \mathrm{~h}$ & $\begin{array}{llll}0 & 1 & 2 & 3\end{array}$ & $\begin{array}{llll}0 & 1 & 1 & 4\end{array}$ & $\begin{array}{llll}0 & 2 & 3 & 1\end{array}$ & 21112 \\
\hline$p$ value & $<0.05$ & N.S & N.S & N.S \\
\hline
\end{tabular}

$6 \mathrm{~h}$ : group of 6 hours after intravenous infusion; $12 \mathrm{~h}$ : group of 12 hours after intravenous infusion; 18h: group of 18 hours after intravenous infusion; 24h: group of 24 hours after intravenous infusion; "N.S" means no significant difference; numbers in the table means the numbers of observation, $p$ value indicated a significant difference in loss of venous endothelial cells among four groups in different time; "a" means p value which indicated the loss of venous endothelial cells had a significant difference $(\mathrm{p}<0.05)$ between 6 hours and 18 hours, 6 hours and 24 hours.

Figure 2 (6h-24h) showed the photomicrograph of the ears after VCR infusion in different time. Six hours after infusing test solution, there were few inflammatory cells in venous wall or perivascular tissue, more diffused edema, no thrombosis and the loss of venous endothelial cells, which were less than $1 / 3$ of the vein (in cross-section). 12 hours after infusing test solution, few inflammatory cells in venous wall or perivascular tissue were observed; the edema was localized to perivascular tissue and thrombosis was less than $1 / 3$ of vascular sections; the loss of venous endothelial cells were $1 / 3$ to $2 / 3$ of the vein. 18 hours after the test solution, more diffused and dense inflammatory cells infiltrating in perivascular tissue were observed; edema was localized to perivascular tissue; thrombosis occupied more than $2 / 3$ of vascular sections; the loss of venous endothelial cells were observed on $1 / 3$ to $2 / 3$ of the vein. Twenty four hours after the test solution, there were few inflammatory cells in venous wall or 
perivascular tissue, more diffused edema, thrombosis occupying $1 / 3$ to $2 / 3$ of vascular sections and the loss of venous endothelial cells, which were more than $2 / 3$ of the vein.

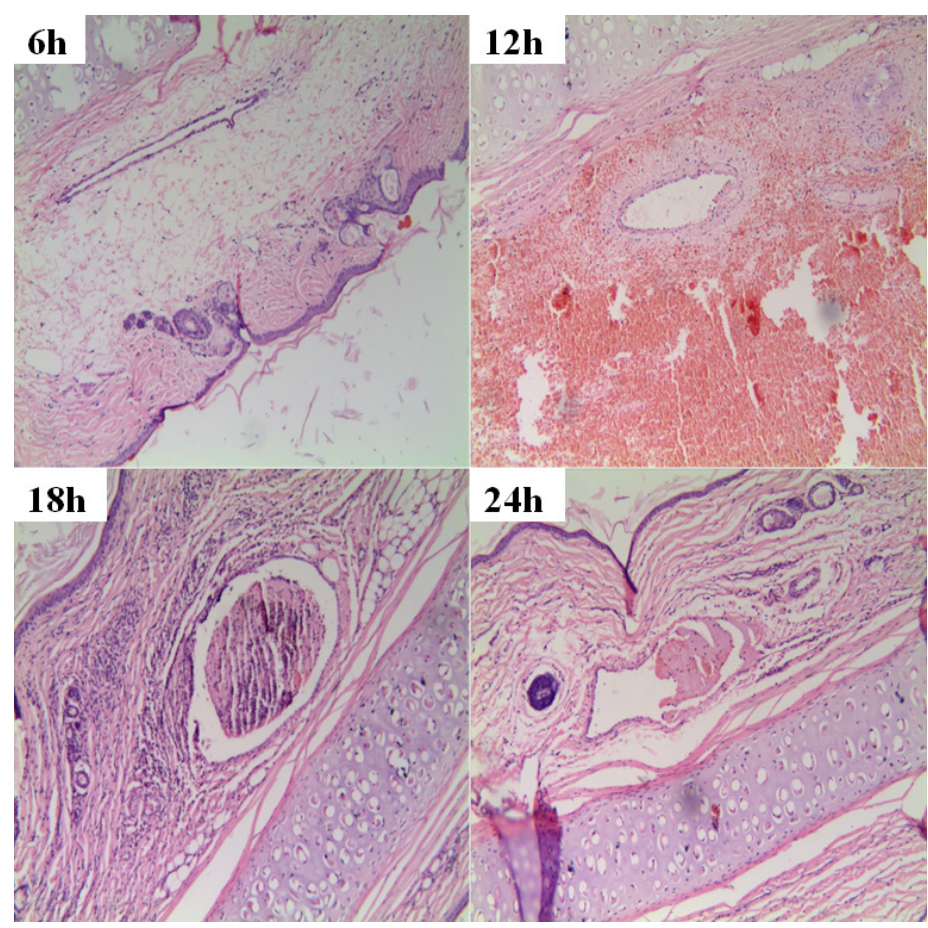

FIGURE 2 - The photomicrigraph from group of 6 hours, 12 hours, 18 hours, 24 hours (hematoxylin and eosin staining; magnification, $\times 100$ ).

\section{Xianchen had effects on preventing phlebitis}

Table 4 summarized the grades of phlebitis 4 days after drugs intervention through macroscopic observation. Among the groups of intervention, there were statistically significant differences $(p<0.05)$; however, the effect of Xianchen group (five times a day) was better than its counterpart (daily) $(p<0.01)$. Grade 1 of phlebitis was more common for Xianchen group (five times a day), but two rabbits had no phlebitis.

TABLE 4 - The grade of phlebitis four days after drugs intervention.

\begin{tabular}{ccccccc}
\hline & $\begin{array}{c}\text { Total numbers of } \\
\text { Intravenous obser- } \\
\text { vadion }\end{array}$ & \multicolumn{6}{c}{ The grades of vein damage } \\
& 6 & 2 & 2 & 1 & 1 & 0 \\
$\mathrm{H}$ & 6 & 0 & 1 & 2 & 3 & 0 \\
$\mathrm{Xd}$ & 6 & 1 & 3 & 1 & 1 & 0 \\
$\mathrm{Xtid}$ & 6 & 3 & 3 & 0 & 0 & 0 \\
$\mathrm{X}^{\mathrm{a}}$ & & \multicolumn{5}{c}{$<0.05$} \\
$p$ value & & \multicolumn{6}{c}{} \\
\hline
\end{tabular}

H: group of Hirudoiod (bid), Xd: group of Xianchen (daily), Xtid: group of Xianchen (tid), X5: group of Xianchen (five times a day); "a" means p value which indicated a significant difference between Xianchen (five times a day) and Xianchen (dialy) $(\mathrm{p}<0.01)$.
From Figure 3H-X5, Hirudoid (bid) showed more diffused edema, loss of venous endothelial cells, less than $1 / 3$ of the vein, few inflammatory cells and no thrombosis. Xianchen (daily) demonstrated few inflammatory cells, edema localized to perivascular tissue, loss of venous endothelial cells less than $1 / 3$ of the vein and thrombosis occupied less than $1 / 3$ of vascular sections. Xianchen (tid) presented more diffused, dense inflammatory cells, no thrombosis, the edema localized to perivascular tissue and loss of venous endothelial cells less than $1 / 3$ of the vein. Xianchen (five times a day) had no significant edema and thrombosis noted, but still few inflammatory cells and loss of venous endothelial cells less than $1 / 3$ of the vein were found.

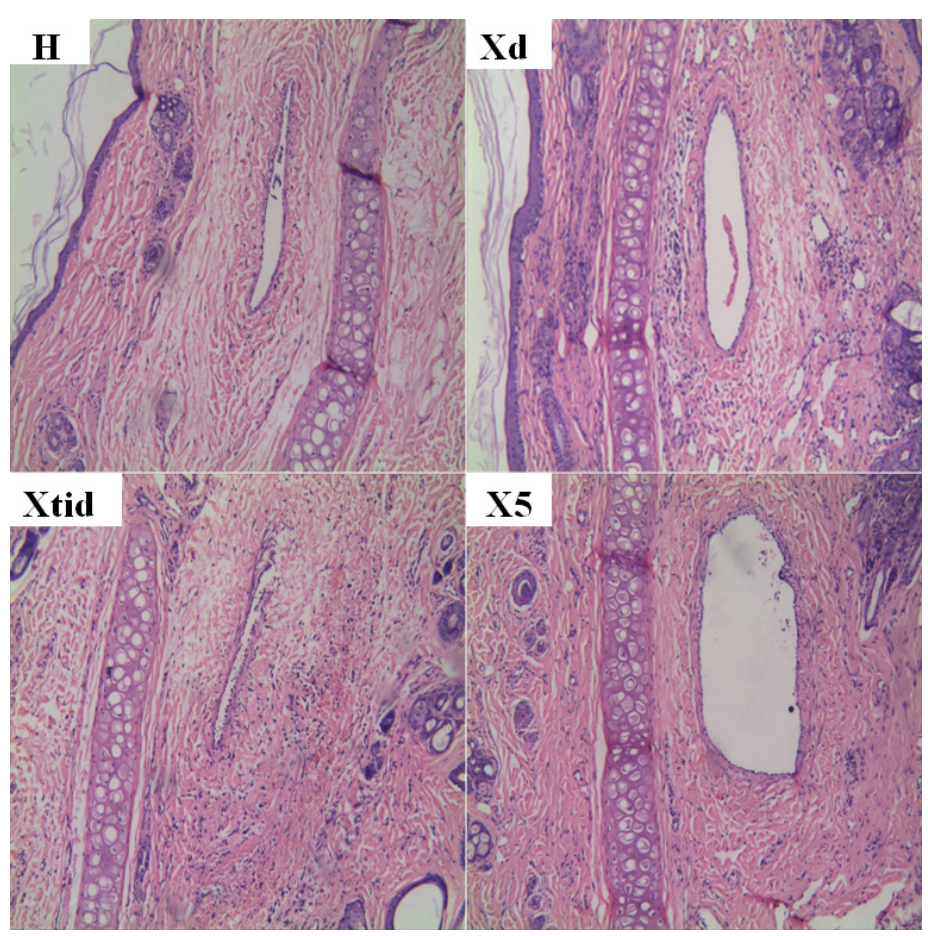

FIGURE 3 - The photomicrigraph from (H) group of Hirudoiod (bid), (Xd) group of Xianchen (daily), (Xtid) group of Xianchen (tid), (X5) group of Xianchen (five times a day) (hematoxylin and eosin staining; magnification, $\times 100$ ).

Table 5 summarized the histopathological findings obtained 4 days after the drugs intervention. The results showed loss of venous endothelial, inflammatory cell, thrombosis, but no statistically significant differences $(p>0.05)$. The effect of the treatment on edema had a significant difference $(p<0.05)$. Xianchen (five times a day) mainly focused on grade 0 to 1 which was better than Hirudoid (bid) $(p<0.05)$, Xianchen five times a day had better effect than its counterpart (daily) $(p<0.05)$. 
TABLE 5 - The pathological grades of phlebitis four days after drugs intervention.

\begin{tabular}{|c|c|c|c|c|}
\hline & $\begin{array}{c}\text { Loss of } \\
\text { venous endo- } \\
\text { thelial cells }\end{array}$ & $\begin{array}{l}\text { Inflamma- } \\
\text { tory cell } \\
\text { infiltration }\end{array}$ & Edema & Thrombosis \\
\hline Grade & $\begin{array}{llll}0 & 1 & 2 & 3\end{array}$ & $\begin{array}{llll}0 & 1 & 2 & 3\end{array}$ & $\begin{array}{llll}0 & 1 & 2 & 3\end{array}$ & $\begin{array}{llll}0 & 1 & 2 & 3\end{array}$ \\
\hline $\mathrm{H}$ & $\begin{array}{llll}0 & 4 & 1 & 1\end{array}$ & $\begin{array}{llll}0 & 2 & 3 & 1\end{array}$ & $\begin{array}{llll}0 & 3 & 2 & 1\end{array}$ & 2310 \\
\hline $\mathrm{Xd}$ & 0222 & $\begin{array}{llll}0 & 1 & 1 & 4\end{array}$ & $\begin{array}{llll}0 & 3 & 1 & 2\end{array}$ & $\begin{array}{llll}12 & 2 & 1\end{array}$ \\
\hline Xtid & $\begin{array}{llll}0 & 4 & 1 & 1\end{array}$ & $\begin{array}{llll}0 & 3 & 1 & 2\end{array}$ & $\begin{array}{llll}0 & 4 & 1 & 1\end{array}$ & 1410 \\
\hline$X 5^{\mathrm{a}}$ & 1320 & 02222 & $\begin{array}{llll}3 & 3 & 0 & 0\end{array}$ & 1230 \\
\hline$p$ value & N.S & N.S & $<0.05$ & N.S \\
\hline
\end{tabular}

H: group of Hirudoiod (bid), Xd: group of Xianchen (daily), Xtid: group of Xianchen (tid), X5: group of Xianchen (five times a day); "N.S" means no significant difference; numbers in the table means the numbers of observation, $p$ value indicated a significant difference in edema among four groups; "a" means $p$ value which indicated the edema had a significant difference between Xianchen (five times a day) and Hirudoid (bid) $(\mathrm{p}<0.05)$, Xianchen (five times a day) and Xianchen (daily) $(\mathrm{p}<0.05)$

\section{Discussion}

Literatures were reported that the mechanism of phlebitis induced by chemotherapeutic drugs involves the following factors: chemotherapeutic drugs reduce vessels' contraction and relaxation function; the vessel wall was ischemic and anoxic, causing changes in permeability; and cellular and chemical toxicity of chemotherapeutic drugs also play a crucial role in formation of phlebitis ${ }^{19}$.

Xianchen made from traditional Chinese herbal can cure chemotherapy induced phlebitis. Its ingredients include pearl, fritillaria, bletilla striata, ginkgo, root bark of peony tree, lonicera japonica, kuh-seng, etc ${ }^{16}$. Fritillaria is proved its effects of detoxification, heat-clearing and phlegm-resolving ${ }^{20}$, and its active constituent is peimine. It also has function of anti-inflammation via inhibiting the production of pro-inflammatory cytokine, such as tumor necrosis factor-alpha (TNF- $\alpha$ ), interleukin (IL)-6, IL-8 and IL-1beta (IL-1 $\beta$ ). It was reported peimine was potential for allergic inflammatory reaction mediated by human mast cells(HMC)-1 cells ${ }^{21}$. Bletilla striata presents the roles in antisepsis, promoting blood circulation and stopping bleeding; therefore, it can also be used for wound and mucosa renewal ${ }^{22}$. The bletilla striata was proved that it could promote wound healing due to its active effect of bletillae's polysaccharide. This effects can be achieved through stimulating the proliferation of vein endothelial cells and expression of vacular enthothelial growth factor (VEGF) ${ }^{23}$. Recent studies have suggested that polysaccharide of bletillae accelerated the wound healing by increasing the level of inducible nitric oxide synthase (iNOS), TNF- $\alpha$ and IL- $\beta \mathrm{mRNA}^{24}$. Some research showed that the lonicera japonica had functions of antisepsis, antiinflammation, antipyretic, antiviral, improving wound healing and tissue regeneration. The main active components were chlorogenic acid, caffeic acid, protocatechuic acid, etc. Its antiinflammation effects were mediated by suppressing the production of proinflammatory cytokines and enhancing of anti-inflammatory factors $^{25-27}$.

Although there are many drugs used to treat phlebitis, but most empirical medicines and methods utilized before during or after chemotherapy lack scientific evidence. This study aimed to observe the model of phlebitis induced by chemotherapy within 24 hours and perform drug intervention based on the development process of phlebitis. Phlebitis occurred early within 24 hours through macroscopic observation and pathological examination. The pathological changes of intravascular thrombosis occurred early. One reason for that was the diameter of needle used in the experiment. Another reason was reverse puncture. These two factors could lead to mechanical stimulation of the blood vessel. Therefore, the long time of infusion deteriorated the damage of vascular cavity and contributed to the local thrombosis in the early time under light microscopy. Although the study has shown the ability of clinical workers influenced phlebitis assessment and venous interventions, the mechanism of phlebitis remained unknown. Therefore, it was difficult to recognize the phlebitis in timely manner ${ }^{28}$. This study indicated that the awareness of early detection and early intervention to phlebitis is essential, especially for the chemotherapeutic drugs with toxic effects.

The study results illustrated that curative effects of Hirudoid and Xianchen (daily and tid) within 4 days had no significant difference $(p>0.05)$ in their treatment outcomes of thrombosis, inflammatory cells infiltration and loss of endothelial cells under the light microscopy, but the difference in the effect of treatment in edema was significant $(p<0.05)$. Xianchen (five times a day) had the better curative effect than Hirudoid (bid) in alleviating edema. Studies showed that Hirudoid has widely been used in clinic, but it caused discomfort. In a three-level of hospital in China, not all nurses were able to use Hirudoid to treat phlebitis in a correct way. They considered that the time to apply Hirudoid was too long, usually five minutes. Nurses could not complete the corresponding work in the limited time. Some patients did not like the smell and character of Hirudiod. They felt uncomfortable after applied it. These contributed to incompliance with the use of this medicine, finally causing the occurrence of phlebitis $^{29}$. In this research, Xianchen was more exquisite and had faster absorbability on phlebitis, especially demonstrating the better therapeutic effects on edema. 
Currently, there are no completely effective measures to prevent phlebitis induced by chemotherapeutic agents. Therefore, early detection and appropriate management are major tasks for nursing care for patients with chemotherapy. Xianchen can be recommendable in clinic settings due to its significant curative effect on treating edema of phlebitis and its noninvasive, topical application, but the exact mechanism still needs further research in later experiments.

\section{Conclusions}

The inflammatory reaction of phlebitis appeared early. Xianchen can treat vincristine induced phlebitis, as well as Hirudoid. It is particularly effective in the treatment of edema, and there is a remarkable dose-response relationship. This study supported that nurses should focus on the early prevention of vincristine induced phlebitis.

\section{References}

1. Nekuzad N, Ashke Torab T, Mojab F, Alavi-Majd H, Azadeh P, Ehtejab G. Effect of external use of sesame oil in the prevention of chemotherapy-induced phlebitis. Iran J Pharm Res. 2012 Fall;11(4):1065-71. PMID: 24250538

2. Wang Z, Ma L, Wang X, Cai H, Cai H, Huang J, Liu J, Hu J, Su D. Cimetidine attenuates vinorelbine-induced phlebitis in mice by militating E-selectin expression. Cancer Chemother Pharmacol. 2014 Aug;74(2):239-47. PMID: 24879290.

3. Infusion Nurses Society. Infusion nursing standards of practice. J Infus Nurs. 2006 Jan-Feb;29(1 Suppl):S1-92. PMID: 16429002.

4. Stutchbury TK, Vine KL, Locke JM, Chrisp JS, Bremner JB, Clingan PR, Ranson M. Preclinical evaluation of novel, all-in-one formulations of 5-fluorouracil and folinic acid with reduced toxicity profiles. Anticancer Drugs. 2011 Jan;22(1):24-34. PMID: 20881836.

5. Ovadje P, Ma D, Tremblay P, Roma A, Steckle M, Guerrero JA, Arnason JT, Pandey S. Evaluation of the efficacy \& biochemical mechanism of cell death induction by piper longum extract selectively in in-vitro and in-vivo models of human cancer cells. PLoS One. 2014 Nov 17;9(11):e113250. PMID: 25401766.

6. Peng J, Qi T, Liao J, Chu B, Chu B, Yang Q, Li W, Qu Y, Luo F, Qian $\mathrm{Z}$. Controlled release of cisplatin from $\mathrm{pH}$-thermal dual responsive nanogels. Biomaterials. 2013 Nov;34(34):8726-40. PMID: 23948167.

7. Yoh K, Niho S, Goto K, Ohmatsu H, Kubota K, Kakinuma R, Saijo N, Nishiwaki Y. Randomized trial of drip infusion versus bolus inject- ion of vinorelbine for the control of local venous toxicity. Lung Cancer. 2007 Mar;55(3):337-41. PMID: 17126951.

8. Gad E, Rastetter L, Slota M, Ohmatsu H, Kubota K, Kakinuma R, Saijo N, Nishiwaki Y. Natural history of tumor growth and immune modulation in common spontaneous murine mammary tumor models. Lung Cancer. 2007 Mar;55(3):337-41. PMID: 17126951.

9. Trendowski M. Using cytochalasins to improve current chemotherapeutic approaches. Anticancer Agents Med Chem. 2015;15(3):327-35. PMID: 25322987.

10. Curran CF, Luce JK, Page JA. Doxorubicin-associated flare reactions. Oncol Nurs Forum. 1990 May-Jun;17(3):387-9. PMID: 2342972.
11. Kohno E, Murase S, Matsuyama K, Okamura N. Effect of corticosteroid on phlebitis induced by intravenous infusion of antineoplastic agents in rabbits. Int J Med Sci. 2009 Aug 6;6(5):21823. PMID: 19680474.

12. Zhang Feifei, Wei Yiping, Gao Wen, Guan Ying, Liao Hai-tao. Experimental study on influence of different drug administration modes on vincristine induced phlebitis. Chinese Nursing Research. 2011 Apr;25(4):856-8. doi: 10.3969/j.issn.1009-6493.2011.10.005.

13. Sha S, Liu W, Cheng L, Ge J. Review of traditional Chinese medicine external applications to treat chemistry phlebitis. Zhongguo Zhong Yao Za Zhi. 2011 Sep;36(18):2592-4. PMID: 22256773.

14. Li Guo-hui, Jia Ying-jie, Su Shuang, Xia Kun. Evidence-based pharmacy evaluation of ruyi jinghuang powder for treating phlebitis. Chin Pharm J. 2012 Nov;47(22):1860-4.

15. Min Qiu, Jian Ying, Li Liu. Clinical effect of the protection veins ointment on preventing chempthery phlebitis. Clin J Chin Med. 2014;6(2):29-31. doi: 10.3969/j.issn.1674.7860.2014.02.04.

16. Liu Hao, Li Min, Li Xiao-ming, Yang min, Wu Hua-pu. The study of tinctura Xianchen Fenci Jing in anti-inflammation. J Huaihai Med. 2005 Mar;23(2):99-100. doi: 10.14126/j.cnki.1008-7044. 2005.02.008

17. Kuwahara T, Asanami S, Kubo S: Experimental infusion phlebitis:tolerance osmo- lality of peripheral venous endothelial cells. Nutrition. 1998 Jun;14(6):496-501. PMID: 9646289.

18. Kuwahara T, Asanami S, Kawanchi Y, Kubo S. Experimental infusion phlebitis: tolerance $\mathrm{pH}$ of peripheral vein. J Toxicol Sci. 1999 May;24(2):113-21. PMID: 10349613.

19. Yamada T, Egashira N, Watanabe H, Nagata K, Yano T, Nonaka $\mathrm{T}$, Oishi R. Decrease in the vinorelbine-induced venous irritation by pharmaceutical intervention. Support Care Cancer. 2012 Jul;20(7):1549-53. PMID: 21805382.

20. Xu F, Xu S, Wang L, Chen $\mathrm{C}$, Zhou X, Lu Y, Zhang $\mathrm{H}$. Antinociceptive efficacy of verticinone in murine models of inflammatory pain and paclitaxel induced neuropathic pain. Biol Pharm Bull. 2011;34(9):1377-82. PMID: 21881221.

21. Lee B, Kim EY, Kim JH, Min JH, Jeong DW, Jun JY, Cho CY, Sohn Y, Jung HS. Antiallergic effects of peiminine through the regulation of inflammatory mediators in HMC-1 cells. Immunopharmacol Immunotoxicol. 2015;37(4):351-8. PMID: 26121924.

22. Luo Y, Diao H, Xia S, Dong L, Chen J, Zhang J. A physiologically active polysaccharide hydrogel promotes wound healing. J Biomed Mater Res A. 2010 Jul;94(1):193-204. PMID: 20128009.

23. Wang C, Sun J, Luo Y, Xue W, Diao H, Dong L, Chen J, Zhang J. A polysaccharide isolated from the medicinal herb Bletilla striata induces endothelial cells proliferation and vascular endothelial growth factor expression in vitro. Biotechnol Lett. 2006 Apr;28(8):539-43. PMID: 16614890.

24. Diao H, Li X, Chen J, Luo Y, Chen X, Dong L, Wang C, Zhang C, Zhang J. Bletilla striata polysaccharide stimulates inducible nitric oxide synthase and proinflammatory cytokine expression in macrophages. J Biosci Bioeng. 2008 Feb;105(2):85-9. PMID: 18343332 .

25. Chen WC, Liou SS, Tzeng TF, Lee SL, Liu IM. Wound repair and anti-inflammatory potential of Lonicera japonica in excision wound-induced rats. BMC Complement Altern Med. 2012 Nov 23;12:226. PMID: 23173654

26. Shang X, Pan H, Li M, Miao X, Ding H. Lonicera japonica Thunb: Ethnopharmacology, phytochemistry and pharmacology of an important traditional Chinese medicine. J Ethnopharmacol. 2011 Oct 31;138(1):1-21. PMID: 21864666

27. Tzeng TF, Tzeng YC, Cheng YJ, Liou SS, Liu IM. The ethanol extract from Lonicera japonica Thunb. Regresses nonalcoholic steatohepatitis in a methionine- and choline-deficient diet-fed animal model. Nutrients. 2015 Oct 21;7(10):8670-84. PMID: 26506376. 
Zhang J et al.

28. Woody G, Davis BA: Increasing nurse competence in peripheral intravenous therapy. J Infus Nurs. 2013 Nov-Dec;36(6):413-9. PMID: 24202121.

29. XU Ya-nan, CHEN Xiang-yu, YUAN Ling, YANG Li-hua. Effect of blue cape skin better on prevention of chemotherapy phlebitis caused by chemotherapy drugs. J Nurs. 2014 Mar;21(5):12-4. doi: 10.16460/j.issn1008-9969.2014.05.008.

\section{Correspondence:}

\section{Hao Liu}

Department of Pharmacology, Bengbu Medical College

Bengbu, China

liuhao6886@foxmail.com

Received: Apr 03, 2016

Review: Jun 08, 2016

Accepted: July 11, 2016

Conflict of interest: none

Financial sources: Natural Science Foundation of Anhui (KJ2014A165)

and Innovation Plan of Bengbu Medical College (byycx1419)

${ }^{1}$ Research performed at Department of Nursing, Biochemical Medicine Engineering Technology Research Center, Bengbu, China. 